\title{
openheart Cardiac function associated with previous, current and repeated depression and anxiety symptoms in a healthy population: the HUNT study
}

\author{
L T Gustad, ${ }^{1,2}$ O Bjerkeset, ${ }^{2,3}$ L B Strand, ${ }^{4}$ I Janszky, ${ }^{4,5} \varnothing$ Salvesen, ${ }^{4}$ H Dalen ${ }^{1,6}$
}

To cite: Gustad LT, Bjerkeset 0 , Strand LB, et al. Cardiac function associated with previous, current and repeated depression and anxiety symptoms in a healthy population: the HUNT study. Open Heart 2016;3: e000363. doi:10.1136/ openhrt-2015-000363

Received 17 November 2015 Revised 13 January 2016 Accepted 14 January 2016

\section{(1) CrossMark}

${ }^{1}$ Department of Internal Medicine, Levanger Hospital, Nord-Trøndelag Hospital Trust, Levanger, Norway ${ }^{2}$ Department of

Neuroscience, Norwegian University of Technology and Science (NTNU), Trondheim, Norway

${ }^{3}$ Faculty of Health Sciences, Nord University, Levanger, Norway

${ }^{4}$ Department of Public Health and General Practice, NTNU, Trondheim, Norway

${ }^{5}$ Department of Public Health Sciences, Karolinska Institutet, Stockholm, Sweden

${ }^{6} \mathrm{MI}$ Lab and Department of Circulation and Medical Imaging, Norwegian University of Science and Technology, Trondheim, Norway

Correspondence to Dr L T Gustad;

lise.tuset.gustad@gmail.com

\section{ABSTRACT}

Objective: Symptoms of anxiety and depression often co-exist with cardiovascular disease (CVD), yet little is known about the association with left ventricular (LV) subclinical dysfunction. We aimed to study the crosssectional associations of previous, current and repeated depression or anxiety symptoms, with sensitive indices of LV systolic and diastolic function, based on tissue Doppler (TD) and speckle tracking (ST) imaging methods.

Methods: A random selection of 1296 individuals free from known CVD, hypertension and diabetes were examined with echocardiography at baseline of the third Nord-Trøndelag Health Study, (HUNT3, 20062008). The primary outcomes were LV diastolic function ( $\mathrm{e}^{\prime}$ ) and LV systolic function (Iongitudinal global strain). The primary exposures were self-report on the Hospital Anxiety and Depression Scale (HADS). Associations between outcomes and baseline exposures were available for $1034(80 \%)$, and with previous and repeated exposures for 700 participants who also participated in HUNT2 (1995-1997).

Results: Previous and repeated depression symptoms, but not current depression, were linearly associated with a reduction in $\mathrm{e}^{\prime}$. The average sum of two repeated HADS-D scores 10 years apart had the strongest effect on $\mathrm{e}^{\prime}(-8.3 \% ; 95 \% \mathrm{Cl}-13.9 \%$ to $-2.7 \%$ ) per 5 units. We observed a sex difference between depression symptoms and longitudinal global strain ( $p$ for interaction 0.019), where women had a marginal negative effect. Anxiety symptoms, neither previous, current nor repeated were associated with subclinical LV dysfunction.

Conclusions: In a healthy sample, confirmed free of CVD, past and repeated depression symptoms were associated with subclinical LV dysfunction. Thus, depression symptoms might represent a modifiable risk factor for future CVD.

\section{INTRODUCTION}

Subclinical cardiac dysfunction assessed by tissue Doppler imaging (TDI) is shown to be an independent predictor of future cardiovascular disease (CVD) morbidity and mortality in a general population with normal

\section{KEY QUESTIONS}

What is already known about this subject?

- Subclinical cardiac dysfunction assessed by tissue Doppler imaging (TDI) is shown to be an independent predictor for future cardiovascular disease (CVD). Even though depression or anxiety symptoms may represent modifiable risk factors for future incident CVD, it is not clear if these are markers for subclinical cardiac dysfunction. Only one previous study has examined the association between TDI measures and depression symptoms. That study included subjects with hypertension, metabolic disease and diabetes, all which are potential confounders in the observed association between depression and subclinical cardiac dysfunction.

What does this study add?

- The study adds knowledge about the association between depression and anxiety symptoms with TDI measures in a population confirmed free of CVD. Previous and repeated depression symptoms, but not current depression symptoms, were associated with subclinical diastolic dysfunction measured by $e^{\prime}$ in both sexes, and marginally with subclinical systolic function measured by longitudinal global strain in women. Neither current nor recurrent anxiety symptoms were associated with subclinical left ventricular cardiac function.

How might this impact clinical practice?

- Previous and repeated depression symptoms might represent a modifiable risk factor for future CVD. Women might be more prone than men to develop systolic dysfunction due to prolonged depression symptoms.

conventional echocardiographic examinations. ${ }^{1}$ Even though depression and anxiety symptoms are associated with increased risk for future incidence of CVD,$^{2-7}$ it is not clear if these are markers for subclinical cardiac dysfunction. There are many plausible pathogenic mechanisms for anxiety and 
depression symptoms to represent early modifiable risk factors for CVD, including neurohormonal stress, inflammation and behaviour. ${ }^{8-10}$

To the best of our knowledge, no study has examined the association of anxiety symptoms and subclinical cardiac dysfunction measured by echocardiography or MRI, and only one study has examined depression symptoms in this context. ${ }^{11}$ Kim et $a l^{11}$ previously found that early left ventricular (LV) diastolic function was reduced in participants with mild or moderate depression symptoms compared to in participants with no depression symptoms. However, they ${ }^{11}$ included people with hypertension, diabetes and metabolic syndrome, all which may cause both the presence of subclinical cardiac dysfunction ${ }^{12-14}$ and depression symptoms. ${ }^{15}$ Depression is known to have a recurrent nature. ${ }^{15}$ Limited evidence suggests that repeated episodes of depression or anxiety symptoms might be more strongly associated with CVD than single depressive episodes. $^{4} 71617$

Therefore, our aim was to investigate the associations of previous, current and repeated reports of anxiety or depression with sensitive indices of LV systolic and diastolic function in a random sample of healthy adults.

\section{METHODS}

\section{Study population and setting}

All 93210 citizens aged $\geq 20$ years in Nord-Trøndelag County, Norway, received a postal invitation to participate in the third wave of HUNT (HUNT3, 2006-2008, http://www.ntnu.edu/hunt). In total, 50807 (54.1\%) people participated. ${ }^{18}$ Within the HUNT3 study, 1296 participants were randomly selected for the echocardiography study. The sample size was based on suitability in order to obtain normal reference values of the different LV indices by age groups, and to study the associations of cardiac indices with traditional cardiac risk factors. ${ }^{19} 20$ Participants were randomised for examination with echocardiography when they attended the baseline clinical examination at the study centres. ${ }^{12} 19-21$ To be eligible, participants had to be free from known CVD, diabetes and hypertension. ${ }^{12}{ }^{19-21}$ The participants' medical history was validated by an experienced physician echocardiographer (HD). Furthermore, 30 participants were excluded due to significant pathology that could influence the LV function indices. Thus, the total number of healthy individuals with normal echocardiographic findings was $1266 .^{19}$

The study was approved by the Regional Committee for Medical and Health Research Ethics, and the HUNT Publication Board.

\section{Current and repeated symptoms of anxiety or depression}

At the HUNT3 examination, the participants received additional health-related questionnaires, which included reporting of anxiety and depression symptoms. These questionnaires were taken home by participants, filled in and returned by post in a prepaid envelope. ${ }^{18}$ The participants were instructed to report how they felt during the past week, using the Hospital Anxiety and Depression Scale (HADS). ${ }^{22}$ Seven questions mirrored depressed mood (HADS-D), and seven questions mirrored anxiety symptoms such as worry and restlessness (HADS-A) ${ }^{23}$ Each subscale has a four-point Likert scale, ranging from 0 (no symptom) to 3 (highest symptom level), which add up to a score range from 0 to 21 points. Valid HADS-D and HADS-A scores were defined as 5 or more questions answered on each subscale. Missing responses among those who filled in 6 or 5 items were replaced based on the sum of completed items multiplied by $7 / 6$ or $7 / 5$, respectively. In total, $1034(82 \%)$ individuals (544 women) from the echocardiographic study had valid current HADS symptom scores in HUNT3 and constitute the study population in this study (see figure 1).

Previous HADS-A and HADS-D symptoms were available for $700(68 \%)$ individuals (357 women) from their participation in HUNT2 (1995-1997). To reflect the combined burden of two repeated measurements, we averaged the sum from each HADS subscale in HUNT2 and HUNT3.

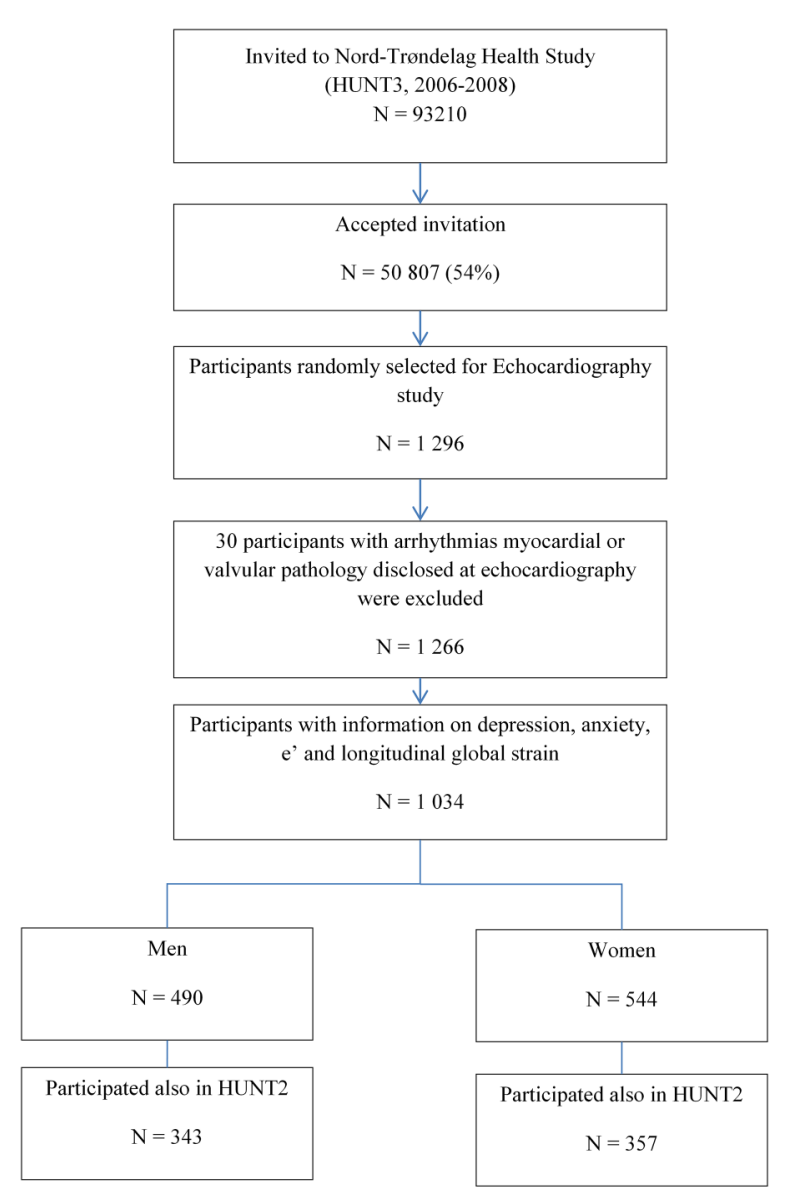

Figure 1 Flow chart of study recruitment. 


\section{Covariates}

Demographic and lifestyle factors

Demographic and lifestyle factors were assessed from the baseline examination in HUNT3. Marital status was categorised into never married, married or living with partner, and separated/divorced/widowed.

Education was categorised as elementary school ( $\leq 9$ years), high school (10-12 years) and university (>12 years). Smoking was categorised into current, previous or never smoking. A validated index for leisure-time physical activity was calculated as a product of exercise frequency, exercise intensity and training session duration. ${ }^{24}$

\section{Clinical examination}

A clinical baseline examination was performed by trained nurses according to a standardised protocol. ${ }^{18}$ Systolic and diastolic blood pressures were measured three times, after the participant had been seated for at least 2 min with the cuff on, with cuff size adjusted for arm circumference. All blood pressure measurements were performed with the Dinamap 845XT (Criticon) based on oscillometry. The average of the second and third measurement was used in the analyses. Height was measured without shoes to the nearest $1 \mathrm{~cm}$ and weight with light clothing to the nearest $0.5 \mathrm{~kg}$. Body mass index (BMI) was computed as weight (in $\mathrm{kg}$ ) divided by the squared value of height (in metres). ${ }^{18}$

\section{Echocardiographic acquisition, analyses and reproducibility}

The participants waited about $1 \mathrm{~h}$ without smoking or eating at the study site before the echocardiography. The mean time since the last meal was $2.8 \mathrm{~h}$ (SD 2.1). ${ }^{19}$ All examinations were conducted by an experienced physician echocardiographer (HD) and the participants were examined in the left lateral decubitus position with a high-end scanner (Vivid 7, version BT06; GE Vingmed Ultrasound AS, Horten, Norway), using a phased-array transducer (M3S and M4S). All the presented echocardiographic measurements were available in $\geq 96 \%$ of the participants. ${ }^{19}$ All echocardiographic data were stored digitally and subsequently analysed.

LV function was assessed by several well-established echocardiographic indices of systolic and diastolic longitudinal function. LV end-systolic global strain (longitudinal global strain) refers to percentage of longitudinal shortening of the myocardium of the LV during systole, and LV peak global strain rate (longitudinal global strain rate) refers to the respective maximal speed of longitudinal global strain. Both indices were assessed by tracking of seven regions of interest in each of the three apical standard views of the LV by customised software (GcMat; GE Vingmed Ultrasound, Norway). The method used combined tissue Doppler (TD) for tracking along the ultrasound beam, and tracking of greyscale speckles (speckle tracking (ST)) for tracking of the regions of interest perpendicular to the ultrasound beam. ${ }^{19}$ Longitudinal global strain and global strain rate are both presented as the average of segmental values when assessed in a 16 segment model of the $\mathrm{LV}^{25}$

Further, peak mitral annular systolic velocity $\left(\mathrm{s}^{\prime}\right)$ and peak mitral annular early diastolic velocities $\left(e^{\prime}\right)$ were measured in the base of the $\mathrm{LV}$ wall by pulsed wave TD. The average of the inferoseptal, lateral, anterior and inferior locations was used in the analyses. ${ }^{12}$ Correspondingly, mitral annular plane systolic excursion (MAPSE) was measured as the average of the total systolic cumulative excursion of the same locations. ${ }^{20}$ Left atrial volume index (for 200 participants) and LV mass were measured in unidimensional M-mode in the parasternal long axis view. The $\mathrm{LV}$ mass was calculated by the Cube formula: $\mathrm{LV}$ mass $=0.8 \times 1.04 \times[$ (intraventricular septum $+\mathrm{LV}$ internal diameter+inferolateral wall thickness $)^{3}-(\mathrm{LV}$ internal diameter $\left.)^{3}\right]+0.6 \mathrm{~g}^{25}$ Ejection fraction $(\mathrm{EF})$ was analysed by calculation of end-diastolic and end-systolic $\mathrm{LV}$ volumes from tracings in the four-chamber and twochamber view.

The reproducibility of the echocardiographic measures was excellent, with $4-8 \%$ interobserver mean errors and $2-5 \%$ intraobserver mean errors. ${ }^{20} 21$

\section{Statistical analysis}

Clinical echocardiographic data followed a normal distribution and are presented as mean (SD). Based on previous knowledge, longitudinal global strain was expected to be the most sensitive index to detect systolic dysfunction and $\mathrm{e}^{\prime}$ the most sensitive for detecting LV diastolic dysfunction. ${ }^{12}$ Thus, an a priori decision was made to include these as the main analyses and include the other LV indices as secondary analyses. The HADS-scores were operationalised as continuous variables in all analyses. Univariate Spearman correlations were performed between all HADS-measures and LV function measures. Linear regression analyses were performed to estimate the multivariate associations of depression and anxiety symptoms with the different $\mathrm{LV}$ function indices. All LV function indices were mutually correlated ( $\mathrm{r}$ 0.21-0.61, all $\mathrm{p}<0.001)$. The LV function measures were $\log$ transformed in order to present all regression coefficients as the percentage difference in the different LV indices per specified 5 unit (95\% CIs) difference in the HADS-scores. All models were adjusted for sex, age and average heart rate during echocardiography as potentially confounding factors. In model 2, we also adjusted for potential socioeconomic confounders (ie, education and marital status). In model 3, established cardiovascular risk factors such as blood pressure, BMI, smoking and physical activity index were included. We investigated the potential effect modification by sex and age (dichotomised at 50 years of age). There were signs of effect modification between sex and longitudinal global strain $(p=0.019)$, and thus we carried out separate analyses in women and men.

All statistical analyses were performed in Stata IC/12.1 for Windows (Stata Corp LP). 


\section{RESULTS}

Table 1 displays the characteristics of the study participants at baseline. Using the cut-off recommended to ensure depression and anxiety specificity, that is, a score $\geq 11$ on the HADS-D and HADS-A, respectively, only 17 $(1.6 \%)$ had depression and $30(2.9 \%)$ had anxiety symptoms. It has earlier been found ${ }^{3}{ }^{4}$ that the total HUNT population has approximately twice this level of anxiety and depression symptoms.

Table 2 shows that current HADS-D score was associated with lower $\mathrm{e}^{\prime}$ than current HADS-A score $(-2.5 \%$ vs $-1.6 \%$ per 5 units higher HADS), yet the statistical evidence for such an association was weak for both scales. For previous HADS-D scores, $\mathrm{e}^{\prime}$ was $4.8 \%$ lower per 5 units and for the averaged sum of two repeated HADS-D scores, $\mathrm{e}^{\prime}$ was approximately $10 \%$ lower per 5 units in multivariable models. In contrast, the average of two repeated anxiety reports did not show any association with $\mathrm{e}^{\prime}$. The results from analyses after adjusting for potential socioeconomic confounders (model 2) were similar to those in model 1 . Multivariable adjustment including traditional CVD risk factors such as systolic blood pressure, BMI, smoking, physical activity index and heart rate during echocardiography (model 3 ), attenuated the associations Figure 2.

Table 3 shows that the average sums of two depression reports, but not of two anxiety reports, have a marginal negative influence $(-4 \%, 95 \%$ CI $-8.3 \%$ to $-0.3 \%)$ on longitudinal global strain in women but not in men. The point estimate with multivariable adjustments was unchanged, but the statistical evidence was weaker.

There were no associations between any of the HADS-measures and secondary measures of cardiac function ( $\mathrm{s}^{\prime}$, longitudinal global strain rate, MAPSE and LV mass) in crude or fully adjusted models (data not shown).

\section{DISCUSSION}

In the present study of a healthy adult population-based sample, we found that previous and repeated depression scores were associated with lower diastolic LV function measured by $\mathrm{e}^{\prime}$ in both sexes. It also shows a marginally lowered systolic dysfunction measured by longitudinal

\begin{tabular}{|c|c|c|c|}
\hline Variable & $\mathbf{N}$ & $\begin{array}{l}\text { Women } \\
\mathrm{N}(\%)\end{array}$ & $\begin{array}{l}\text { Men } \\
\mathrm{N}(\%) \\
\end{array}$ \\
\hline Sex (n) & 1034 & $544(52.6)$ & $490(47.4)$ \\
\hline Smoking & 1018 & & \\
\hline Never & & $239(44.6)$ & $252(52.2)$ \\
\hline Former & & $163(30.4)$ & $124(25.7)$ \\
\hline Current & & $134(25.0)$ & $106(21.9)$ \\
\hline Marital status & 1031 & & \\
\hline Never married & & $127(23.5)$ & $101(20.7)$ \\
\hline Married & & 327 (60.3) & $321(65.6)$ \\
\hline Separated/divorced/widowed & & $88(16.2)$ & $67(13.7)$ \\
\hline Education (years) & 1025 & & \\
\hline$\geq 9$ & & $83(15.4)$ & $54(11.1)$ \\
\hline $10-12$ & & $273(50.7)$ & $265(54.4)$ \\
\hline \multirow[t]{2}{*}{$>12$} & & $182(33.8)$ & $168(34.5)$ \\
\hline & & Mean (SD) & Mean (SD) \\
\hline Age (years) & 1034 & $50.4(14.1)$ & $50.2(13.4)$ \\
\hline Body mass index $\left(\mathrm{kg} / \mathrm{m}^{2}\right)$ & 1031 & $26.4(4.0)$ & $26.4(3.8)$ \\
\hline Physical activity index & 906 & $0.7(0.8)$ & $0.7(0.8)$ \\
\hline Systolic blood pressure $(\mathrm{mm} \mathrm{Hg})$ & 1024 & $127.3(17.1)$ & $135.0(14.0)$ \\
\hline Diastolic blood pressure $(\mathrm{mm} \mathrm{Hg})$ & 1024 & $71.3(11.6)$ & $78.1(11.2)$ \\
\hline Resting heart rate $(\mathrm{bpm})$ & 1026 & $70.7(11.2)$ & $66.2(11.1)$ \\
\hline Total serum cholesterol ( $\mathrm{mmol} / \mathrm{L})$ & 1028 & $5.6(1.0)$ & $5.6(1.0)$ \\
\hline HADS-Depression (0-21) & 1034 & $2.9(2.8)$ & $2.6(2.5)$ \\
\hline HADS-Anxiety (0-21) & 1034 & $3.7(3.0)$ & $3.5(2.8)$ \\
\hline Ejection fraction (EF) & 1011 & $64.7(10.1)$ & $65.1(9.6)$ \\
\hline Mitral annular plane systolic excursion (MAPSE) $(\mathrm{cm})$ & 1034 & $1.6(0.3)$ & $1.6(0.2)$ \\
\hline Longitudinal global strain (\%) & 1034 & $-17.4(2.3)$ & $-15.9(2.2)$ \\
\hline Longitudinal global strain rate (/s) & 1018 & $-1.0(-0.1)$ & $-1.0(-0.1)$ \\
\hline Systolic annular velocity $\left(\mathrm{s}^{\prime}\right)(\mathrm{cm} / \mathrm{s})$ & 1023 & $8.2(1.2)$ & $8.6(1.4)$ \\
\hline Diastolic annular velocity $\left(\mathrm{e}^{\prime}\right)(\mathrm{cm} / \mathrm{s})$ & 1023 & $11.9(3.2)$ & $10.7(3.1)$ \\
\hline Left ventricular mass index $(\mathrm{g})$ & 1015 & $162.0(51.5)$ & $162.7(49.5)$ \\
\hline Left atrial volume index $(\mathrm{g})$ & 200 & $3.6(0.1)$ & $3.6(0.1)$ \\
\hline
\end{tabular}


Table 2 Linear regression analysis for the \% difference in early diastolic velocity (e') per 5 unit rise in HADS-scores

\begin{tabular}{|c|c|c|c|c|}
\hline & \multicolumn{2}{|r|}{ Model 1} & \multicolumn{2}{|r|}{ Model 3} \\
\hline & $\mathbf{N}$ & $\begin{array}{l}\mathrm{B}=\% \text { difference per } 5 \text { HADS } \\
\text { units }(95 \% \mathrm{Cl})\end{array}$ & $\mathbf{N}$ & $\begin{array}{l}\mathrm{B}=\% \text { difference per } 5 \text { HADS } \\
\text { units }(95 \% \mathrm{Cl})\end{array}$ \\
\hline HADS-D & 996 & $-2.5(-6.1$ to 0.1$)$ & 844 & $-1.9(-7.5$ to 3.6$)$ \\
\hline HADS-D ${ }^{P}$ & 675 & $-7.4(-8.8$ to -0.8$)$ & 566 & $-4.8(-8.8$ to -0.8$)$ \\
\hline HADS-D ${ }^{R}$ & 675 & $-10.3(-15.8$ to -4.9$)$ & 566 & $-8.3(-13.9$ to -2.7$)$ \\
\hline HADS-A & 995 & $-1.6(-4.7$ to 1.6$)$ & 844 & $-1.9(-5.1$ to 1.28$)$ \\
\hline HADS-A ${ }^{P}$ & 652 & $-0.2(-3.9$ to 3.4$)$ & 564 & $-2.0(-3.9$ to 3.4$)$ \\
\hline HADS-A ${ }^{R}$ & 652 & $-1.7(-6.8$ to 2.5$)$ & 547 & $-1.4(-6.5$ to 3.8$)$ \\
\hline
\end{tabular}

Model 1: Age, sex, resting heart rate. Model 2: Model $1+$ Marital status and education (data not shown). Model 3: Model $2+$ systolic blood pressure, body mass index, smoking, physical activity index.

HADS-D, HADS-depression report from HUNT3; HADS-DP, Previous HADS-D report from HUNT2; HADS-D ${ }^{R}$, Repeated HADS-D reports (average sum score of two reports of HADS-D from HUNT2 + HUNT3); HADS-A, HADS-anxiety reports from HUNT3; HADS-A ${ }^{P}$, Previous HADS-A report from HUNT2; HADS-A ${ }^{\mathrm{R}}$, Repeated HADS-A reports (average sum score of two reports of HADS-A from HUNT2 + HUNT3).

global strain in women. However, current symptoms of depression or anxiety had no consistent associations with subclinical LV dysfunction. As the study population only consisted of healthy individuals, the effect of previous and repeated depression symptoms is unlikely to be caused by reverse causality or existing disease. Further research is needed before definitive conclusions are drawn.

\section{Comparisons with previous studies}

To the best of our knowledge, only one previous echocardiographic study ${ }^{11}$ has assessed the association of current depression symptoms with novel echocardiographic parameters. No study has assessed the impact of anxiety symptoms or repeated measures of anxiety and depression symptoms. Kim et $a l^{11}$ found that, in an older population with complex medical comorbidity (hypertension, diabetes mellitus and metabolic syndrome), the prevalence of moderate to severe depression symptoms was about 5\%. Those who had moderate to severe depression had a $4 \%$ reduction $(95 \%$ CI $2 \%$ to $7 \%$ reduction) in LV diastolic function measured by $\mathrm{e}^{\prime}$ compared to those with no depression symptoms. ${ }^{11}$ Our

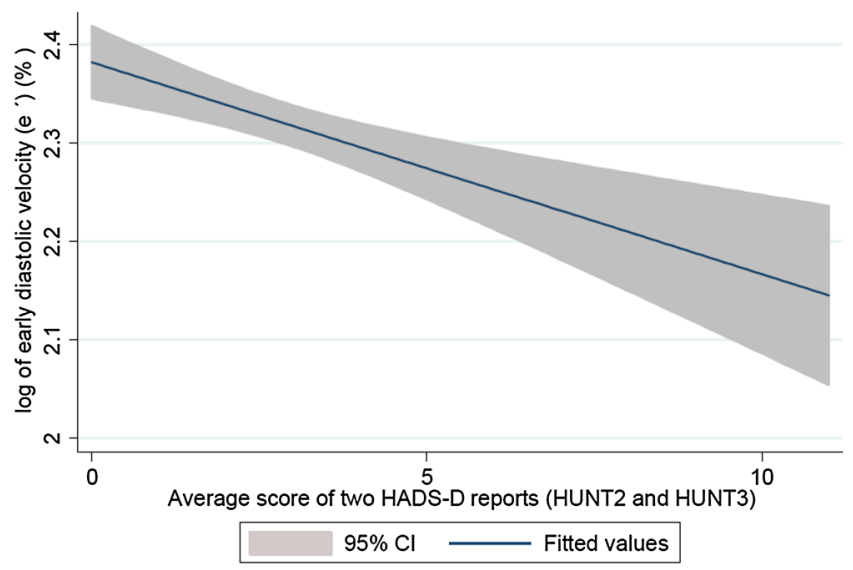

Figure 2 Association of early diastolic velocity (\%) with higher averaged score of two repeated HADS-D reports. findings on previous and repeated depression symptoms and cardiac function are in line with Kim et $a l^{11}$; both studies find LV systolic function indices to be less affected than diastolic indices. The indices of LV diastolic and systolic function used in this study, $\mathrm{e}^{\prime}$ and longitudinal global strain, were chosen a priori, based on previous knowledge of the high sensitivity for these measures to detect subclinical cardiac dysfunction ${ }^{12}$ that are clinically relevant for prediction of future CVD. ${ }^{1}$ Longitudinal strain and $\mathrm{e}^{\prime}$ are linked to various CVD risk factors and manifest CVD even though other indices of LV systolic and diastolic function have been less influenced. ${ }^{1} 12$ 26-28

The differential associations for previous, repeated versus current depression symptoms with cardiac dysfunction, might have several explanations. First, our population had a lower prevalence of baseline depression symptoms than that in the study by Kim $e t a l,{ }^{11}$ thus the different results could reflect a dose-response issue. Second, previous research suggests that the relationship between depression and anxiety symptoms with CVD morbidity follows dose-response manners, not only in terms of symptom level on one occasion, ${ }^{4}$ but also with symptom duration. ${ }^{4} 16 \quad 17 \quad 29 \quad 30$ Both previous and repeated depression symptoms include possibilities for longer symptom duration than current depression symptoms. Longer symptom duration is associated with a chronic stress response, including increased proinflammatory cytokines and neurohormonal stress activity, which both negatively affect development towards CVD disease. ${ }^{9} 31$ Third, as repeated depression symptoms are associated with the most negative effect, it could be hypothesised that a high score on one anxiety and depression report could reflect a normal reaction to stressful events, while high levels on both HUNT waves may better capture cardiac risk related to depression symptoms. ${ }^{4}$

In this study, women, but not men, were prone to have subclinical LV systolic dysfunction associated with repeated depression symptoms. One could speculate whether this difference is due to altered 
Table 3 Linear regression analysis for the \% difference in longitudinal global strain per 5 unit rise in HADS-scores

\begin{tabular}{|c|c|c|c|c|c|c|c|c|}
\hline & \multicolumn{4}{|c|}{ Women } & \multicolumn{4}{|c|}{ Men } \\
\hline & \multicolumn{2}{|r|}{ Model 1 ( $n=459)$} & \multicolumn{2}{|c|}{ Model 3 ( $n=459)$} & \multicolumn{2}{|c|}{ Model 1 ( $n=459)$} & \multicolumn{2}{|c|}{ Model 3 (n=459) } \\
\hline & $\mathbf{N}$ & $\begin{array}{l}\text { B=\% difference } \\
\text { per } 5 \text { HADS units } \\
(95 \% \mathrm{Cl})\end{array}$ & $\mathbf{N}$ & $\begin{array}{l}B=\% \text { difference } \\
\text { per } 5 \text { HADS } \\
\text { units }(95 \% \mathrm{CI})\end{array}$ & $\mathbf{N}$ & $\begin{array}{l}B=\% \text { difference } \\
\text { per } 5 \text { HADS } \\
\text { units }(95 \% \mathrm{Cl})\end{array}$ & $\mathbf{N}$ & $\begin{array}{l}\text { B=\% difference } \\
\text { per } 5 \text { HADS } \\
\text { units }(95 \% \mathrm{Cl})\end{array}$ \\
\hline HADS-D & 526 & $-1.1(-3.3$ to 1.1$)$ & 445 & $-0.6(-2.8$ to 1.7$)$ & 482 & $3.4(-0.8$ to 6.0$)$ & 408 & $3.3(-0.4$ to 6.1$)$ \\
\hline HADS-D ${ }^{P}$ & 346 & $-3.0(-5.9$ to -0.1$)$ & 289 & $-1.9(-4.8$ to 1.5$)$ & 336 & $-2.7(-5.4$ to 0.1$)$ & 281 & $-1.9(-4.8$ to 1.1$)$ \\
\hline HADS-D ${ }^{R}$ & 346 & $-4.3(-8.3$ to -0.3$)$ & 289 & $-4.3(-7.2$ to 1.4$)$ & 336 & $-0.5(-4.5$ to 3.5$)$ & 281 & $0.1(-4.2$ to 4.3$)$ \\
\hline HADS-A & 526 & $-0.8(-2.8$ to 1.2$)$ & 445 & $-0.8(-2.9$ to 1.3$)$ & 482 & $1.1(-1.2$ to 3.4$)$ & 408 & 0.6 (-1.9 to 3.2$)$ \\
\hline HADS-A ${ }^{P}$ & 329 & $-1.2(-3.8$ to 1.4$)$ & 274 & $-1.7(-4.4$ to 1.0$)$ & 329 & $-0.2(-3.9$ to 1.7$)$ & 274 & $-1.2(4.2$ to 1.7$)$ \\
\hline HADS-A ${ }^{R}$ & 329 & $-2.1(-9.1$ to 1.6$)$ & 274 & $-2.7(-6.6$ to 1.3$)$ & 329 & $-1.3(-5.1$ to 2.5$)$ & 274 & $-1.0(-5.2$ to 2.8$)$ \\
\hline
\end{tabular}

Adjustments: Model 1: Age, heart rate during echocardiography. Model 2: Model 1 + marital status and education (data not shown). Model 3: Models $1+2+$ Systolic blood pressure, body mass index, smoking and physical activity index.

HADS-D: HADS-depression report from HUNT3. HADS-DP: Previous HADS-D report from HUNT2. HADS- ${ }^{R}$ : Repeated HADS-D reports (average sum score of two reports of HADS-D from HUNT2 + HUNT3). HADS-A: HADS-anxiety reports from HUNT3. HADS-AP: Previous HADS-A report from HUNT2. HADS-A ${ }^{R}$ : Repeated HADS-A reports (average sum score of two reports of HADS-A from HUNT2 + HUNT3).

pathophysiological responses to depression symptoms in women. ${ }^{32}$ If so, this could be part of the pathway that eventually leads to clinical CVD despite 'clean' coronary arteries in women. ${ }^{33}$ However, as longitudinal strain is a measure that at least partly is adjusted for cardiac size (as strain is shortening per myocardial wall length), this may interfere with observed sex difference.

We found neither previous, current nor repeated anxiety symptoms to be associated with subclinical LV dysfunction. One explanation might be differences in behaviour and biological response, where individuals with anxiety symptoms often seek and cohere with medical and lifestyle advice, while individuals with depression tend to have an unhealthy lifestyle associated with both lower help-seeking and proinflammatory cytokine release, ${ }^{34} 35$ which can adversely affect pathways in the development towards CVD. ${ }^{9} 31$

\section{Strengths and limitations}

This study has apparent strengths, such as a random inclusion of persons free from CVD, diabetes and hypertension, which makes confounding due to complex medical disease less likely than in Kim et $a l^{11}{ }^{11}$ study. Depressive and anxiety symptoms are known to be associated with physical illness. ${ }^{36} 37$ The causal relationship between mental health and physical illness has been proposed to be bidirectional: anxiety and depression may lead to, for example, high-blood pressure due to activation of the stress axis ${ }^{38-40}$; and at the same time, physical illness is associated with inflammatory cytokine release, which is especially shown to induce depression symptoms. $^{9}{ }^{41}$ In addition, the extensive adjustment for potential confounders makes residual confounding due to medical comorbidity less likely. All echocardiograms and analyses were performed by one physician highly experienced in echocardiography and deformation imaging, blinded to information of symptoms of depression and anxiety, as well as to blood pressure and other possible confounding factors.
The study also has some important limitations. The cross-sectional nature of the study does not allow the direction of the association between repeated depression symptoms and lowered diastolic function to be determined. Further, the participants were healthy both with respect to anxiety and depression symptoms, and the results may not necessarily be generalisable to other populations. ${ }^{42}$ We had no reliable information on the participants' use of antidepressants. However, the most common pharmacological treatments (selective serotonin reuptake inhibitors, tricyclic antidepressants, SNRIs) have shown to be relatively safe and effective in cardiac patients. ${ }^{43}$ Thus, we have no reason to believe that potential antidepressive use is causing the observed effects between repeated depression symptoms and $\mathrm{e}^{\prime}$ in these healthy participants.

Non-participants in HUNT3 had more severe depression and anxiety symptoms than did participants. ${ }^{44}$ As only $68 \%$ had repeated reports of depression and anxiety, one could speculate whether those with severe symptoms were less likely to be able to participate at both waves. Thus, the observed association between repeated depression symptoms and $\mathrm{e}^{\prime}$ could be an underestimation of the true effect. Future studies should include samples with higher levels of anxiety and depression in order to better evaluate the influence on LV function.

\section{Perspectives}

A previous study from the HUNT3 echocardiography study allows us to compare the difference in LV function associated with depression symptoms to traditional risk factors for CVD. ${ }^{14}$ A 5-unit higher average score for two HADS-Depression reports gives similar negative influence of LV diastolic function by $\mathrm{e}^{\prime}$ as $32 \mathrm{~mm} \mathrm{Hg}$ higher blood pressure for women and $25 \mathrm{~mm} \mathrm{Hg}$ in men; or 6.8 years and 6.6 years higher age for women and men, respectively. ${ }^{12}$ Compared to the associations of the wellknown CVD risk factors on LV diastolic function, the effect size of repeated high levels of depression 
symptoms is not negligible. Thus, it is interesting that both the SADHART and CREATE trial found that persons with previous history of depression symptoms were especially responsive to medical treatment, ${ }^{45} 46$ and it is plausible that repeated high levels of depression symptoms represent a modifiable risk factor for CVD. In clinical practice, anxiety and depression co-exist, and it is advised to consider both conditions when planning treatment strategies. ${ }^{10}$

\section{CONCLUSION}

Overall, this study found few positive associations between symptoms of anxiety and depression with LV subclinical dysfunction among healthy participants. However, previous and repeated depression symptoms were associated with subclinical LV diastolic dysfunction $\left(\mathrm{e}^{\prime}\right)$, and marginally in women with subclinical systolic dysfunction (longitudinal global strain). As previous subclinical diastolic dysfunction is shown to be an independent predictor for future CVD, future research should monitor levels of depression symptoms over time in order to further establish the role of such modifiable symptoms in the development of cardiac disease.

\section{Twitter Follow Lise Gustad at @lisetugu}

Acknowledgements The Nord-Trøndelag Health Study (The HUNT Study) is a collaboration between HUNT Research Centre (Faculty of Medicine, Norwegian University of Science and Technology NTNU), Nord-Trøndelag County Council, Central Norway Health Authority and the Norwegian Institute of Public Health. The authors also thank the Department for Research and Development and the Department of Internal Medicine, Levanger Hospital, at Nord-Trøndelag Health Trust, for the invaluable support.

Funding LTG is supported by the Liaison Committee of the Central Norway Regional Health Authority.

Competing interests HD held a position at the Medical Imaging Laboratory, NTNU, a Centre of research-based innovation that is funded by the Research Council of Norway and industry. One of the industry partners was GE Vingmed Ultrasound, which contributed to the total budget with 7 million NOK $(6 \%)$ for the 8-year period 2007-2014. The funders played no role in the research planning, design or interpretation.

Ethics approval Regional Committee for Medical and Health Research Ethics, and the HUNT Publication Board.

Provenance and peer review Not commissioned; externally peer reviewed.

Data sharing statement No additional data are available.

Open Access This is an Open Access article distributed in accordance with the Creative Commons Attribution Non Commercial (CC BY-NC 4.0) license, which permits others to distribute, remix, adapt, build upon this work noncommercially, and license their derivative works on different terms, provided the original work is properly cited and the use is non-commercial. See: http:// creativecommons.org/licenses/by-nc/4.0/

\section{REFERENCES}

1. Mogelvang R, Biering-Sørensen T, Jensen JS. Tissue Doppler echocardiography predicts acute myocardial infarction, heart failure, and cardiovascular death in the general population. Eur Heart $J$ Cardiovasc Imaging 2015;16:1331-7.

2. Garfield LD, Scherrer JF, Hauptman PJ, et al. Association of anxiety disorders and depression with incident heart failure. Psychosom Med 2014;76:128-36.
3. Gustad LT, Laugsand LE, Janszky I, et al. Symptoms of anxiety and depression and risk of heart failure: the HUNT Study. Eur $J$ Heart Fail 2014;16:861-70.

4. Gustad LT, Laugsand LE, Janszky I, et al. Symptoms of anxiety and depression and risk of acute myocardial infarction: the HUNT 2 study. Eur Heart J 2014;35:1394-403.

5. Nicholson A, Kuper $\mathrm{H}$, Hemingway $\mathrm{H}$. Depression as an aetiologic and prognostic factor in coronary heart disease: a meta-analysis of 6362 events among 146538 participants in 54 observational studies. Eur Heart J 2006;27:2763-74.

6. Roest AM, Martens EJ, de Jonge P, et al. Anxiety and risk of incident coronary heart disease: a meta-analysis. J Am Coll Cardiol 2010;56:38-46.

7. Seldenrijk A, Vogelzangs N, Batelaan NM, et al. Depression, anxiety and 6-year risk of cardiovascular disease. J Psychosom Res 2015;78:123-9.

8. Black PH. Stress and the inflammatory response: a review of neurogenic inflammation. Brain Behav Immun 2002;16:622-53.

9. Grippo AJ, Johnson AK. Stress, depression and cardiovascular dysregulation: a review of neurobiological mechanisms and the integration of research from preclinical disease models. Stress 2009;12:1-21.

10. Hare DL, Toukhsati SR, Johansson P, et al. Depression and cardiovascular disease: a clinical review. Eur Heart $J$ 2014;35:1365-72.

11. Kim YH, Kim SH, Lim SY, et al. Relationship between depression and subclinical left ventricular changes in the general population. Heart 2012;98:1378-83.

12. Dalen $\mathrm{H}$, Thorstensen A, Romundstad PR, et al. Cardiovascular risk factors and systolic and diastolic cardiac function: a tissue Doppler and speckle tracking echocardiographic study. J Am Soc Echocardiogr 2011;24:322-32.e6.

13. Fang ZY, Yuda S, Anderson V, et al. Echocardiographic detection of early diabetic myocardial disease. J Am Coll Cardiol 2003;41:611-7.

14. Wong CY, O'Moore-Sullivan T, Fang ZY, et al. Myocardial and vascular dysfunction and exercise capacity in the metabolic syndrome. Am J Cardiol 2005;96:1686-91.

15. Carney RM, Freedland KE. Depression, mortality, and medical morbidity in patients with coronary heart disease. Biol Psychiatry 2003;54:241-7.

16. Hamer M, Kivimaki M, Lahiri A, et al. Persistent cognitive depressive symptoms are associated with coronary artery calcification. Atherosclerosis 2010;210:209-13.

17. Lesperance F, Frasure-Smith N, Talajic M. Major depression before and after myocardial infarction: its nature and consequences. Psychosom Med 1996;58:99-110.

18. Krokstad S, Langhammer A, Hveem K, et al. Cohort profile: the HUNT study, Norway. Int J Epidemiol 2013;42:968-77.

19. Dalen H, Thorstensen A, Aase SA, et al. Segmental and global longitudinal strain and strain rate based on echocardiography of 1266 healthy individuals: the HUNT study in Norway. Eur $J$ Echocardiogr 2010;11:176-83.

20. Dalen $\mathrm{H}$, Thorstensen $\mathrm{A}$, Vatten $\mathrm{LJ}$, et al. Reference values and distribution of conventional echocardiographic Doppler measures and longitudinal tissue Doppler velocities in a population free from cardiovascular disease. Circ Cardiovasc Imaging 2010;3:614-22.

21. Thorstensen A, Dalen $\mathrm{H}$, Amundsen $\mathrm{BH}$, et al. Reproducibility in echocardiographic assessment of the left ventricular global and regional function, the HUNT study. Eur J Echocardiogr 2010;11:149-56.

22. Mykletun A, Stordal E, Dahl AA. Hospital Anxiety and Depression (HAD) scale: factor structure, item analyses and internal consistency in a large population. Br J Psychiatry 2001;179:540-4.

23. Zigmond AS, Snaith RP. The hospital anxiety and depression scale. Acta Psychiatr Scand 1983;67:361-70.

24. Kurtze N, Rangul V, Hustvedt BE, et al. Reliability and validity of self-reported physical activity in the Nord-Trøndelag Health Study (HUNT2). Eur J Epidemiol 2007;22:379-87.

25. Lang RM, Badano LP, Mor-Avi V, et al. Recommendations for cardiac chamber quantification by echocardiography in adults: an update from the American Society of Echocardiography and the European Association of Cardiovascular Imaging. Eur Heart J Cardiovasc Imaging 2015;16:233-70.

26. Christiansen JR, Hamre H, Massey R, et al. Left ventricular function in long-term survivors of childhood lymphoma. Am J Cardiol 2014;114:483-90.

27. Marwick TH. Tissue Doppler imaging for evaluation of myocardial function in patients with diabetes mellitus. Curr Opin Cardiol 2004;19:442-6.

28. Ofstad AP, Urheim S, Dalen $\mathrm{H}$, et al. Identification of a definite diabetic cardiomyopathy in type 2 diabetes by comprehensive 
echocardiographic evaluation: a cross-sectional comparison with non-diabetic weight-matched controls. J Diabetes 2015;7:779-90.

29. Penninx BW, Guralnik JM, Mendes de Leon CF, et al. Cardiovascular events and mortality in newly and chronically depressed persons $>70$ years of age. Am J Cardiol 1998;81:988-94.

30. Wassertheil-Smoller S, Applegate WB, Berge K, et al. Change in depression as a precursor of cardiovascular events. SHEP Cooperative Research Group (Systoloc Hypertension in the elderly). Arch Intern Med 1996;156:553-61.

31. Nair N, Farmer C, Gongora E, et al. Commonality between depression and heart failure. Am J Cardiol 2012;109:768-72.

32. Vaccarino V, Shah AJ, Rooks C, et al. Sex differences in mental stress-induced myocardial ischemia in young survivors of an acute myocardial infarction. Psychosom Med 2014;76:171-80.

33. Orth-Gomér K, Deter HC. Sex and gender issues in cardiovascular research. Psychosom Med 2015;77:1067-8.

34. Berk M, Williams LJ, Jacka FN, et al. So depression is an inflammatory disease, but where does the inflammation come from? BMC Med 2013;11:200.

35. Johansen A, Holmen J, Stewart R, et al. Anxiety and depression symptoms in arterial hypertension: the influence of antihypertensive treatment. the HUNT study, Norway. Eur J Epidemiol 2012;27:63-72.

36. Moussavi S, Chatterji S, Verdes E, et al. Depression, chronic diseases, and decrements in health: results from the World Health Surveys. Lancet 2007;370:851-8.

37. Stordal E, Bjelland I, Dahl AA, et al. Anxiety and depression in individuals with somatic health problems. The Nord-Trøndelag Health Study (HUNT). Scand J Prim Health Care 2003;21:136-41.
38. Brotman DJ, Golden SH, Wittstein IS. The cardiovascular toll of stress. Lancet 2007:370:1089-100.

39. Stein DJ, Aguilar-Gaxiola S, Alonso J, et al. Associations between mental disorders and subsequent onset of hypertension. Gen Hosp Psychiatry 2014;36:142-9.

40. Yan LL, Liu K, Matthews KA, et al. Psychosocial factors and risk of hypertension: the Coronary Artery Risk Development in Young Adults (CARDIA) study. JAMA 2003;290:2138-48.

41. Raison $\mathrm{CL}$, Capuron L, Miller AH. Cytokines sing the blues: inflammation and the pathogenesis of depression. Trends Immunol 2006;27:24-31.

42. Vittinghoff E, Glidden DV, Shiboski SC, et al. Regression methods in biostatistics; linear, logistic, survival and repeated measures models. 2nd edn. New York: Springer 2012.

43. Mavrides N, Nemeroff CB. Treatment of affective disorders in cardiac disease. Dialogues Clin Neurosci 2015;17:127-40.

44. Langhammer A, Krokstad S, Romundstad P, et al. The HUNT study: participation is associated with survival and depends on socioeconomic status, diseases and symptoms. BMC Med Res Methodol 2012;12:143.

45. Berkman LF, Blumenthal J, Burg M, et al. Effects of treating depression and low perceived social support on clinical events after myocardial infarction: the Enhancing Recovery in Coronary Heart Disease Patients (ENRICHD) Randomized Trial. JAMA 2003;289:3106-16.

46. Glassman $\mathrm{AH}$, Bigger JT, Gaffney M, et al. Onset of major depression associated with acute coronary syndromes: relationship of onset, major depressive disorder history, and episode severity to sertraline benefit. Arch Gen Psychiatry 2006;63:283-8. 